\title{
Modelling the intention to use technology for teaching mathematics among pre-service teachers in Serbia
}

\author{
Timothy Teo \\ University of Macau \\ Verica Milutinovic \\ University of Kragujevac
}

\begin{abstract}
This study aims to examine the variables that influence Serbian pre-service teachers' intention to use technology to teach mathematics. Using the technology acceptance model (TAM) as the framework, we developed a research model to include subjective norm, knowledge of mathematics, and facilitating conditions as external variables to the TAM. In addition, we investigated the influence of gender and age on the behavioural intention to use technology. With data gathered from 313 participants using a survey questionnaire, structural equation modelling (SEM) analysis revealed that the proposed model in this study has a good fit and accounted for $5.4 \%$ of the variance in the behavioural intention to use technology. Pre-service teachers' attitudes towards computers were found to be the only factor with direct influence on the intention to use technology. All other factors were found to have an indirect influence. Using multiple indicators, multiple causes (MIMIC) modelling, pre-service teachers' intention to use technology was not found to be significantly different by age and gender. Various contributions to research and implications for teacher training are discussed.
\end{abstract}

\section{Introduction}

In today's world, when society is shifting from an industrial towards an information or knowledge society, it is important for students to develop lifelong learning skills, often referred to as a capacity of "learning to learn" (Anderson, 2008, p. 19). Many organisations have implemented initiatives in education, in mathematics in particular, to respond to the challenges in acquiring these new skills (Anderson, 2008; International Society for Technology in Education, 2007; Partnership for 21st Century Skills, n.d.; United Nations Educational, Scientific and Cultural Organization [UNESCO], 2002). Some examples of the desired skills for the 21st century are creativity and innovation, communication and collaboration, research and information fluency, critical thinking, problem solving and decision making, and digital citizenship and technology operations (International Society for Technology in Education, 2007). In preparing for these skills, the appropriate use of technology by teachers in education is crucial.

Despite the strong presence of information and communication technology (ICT) in classrooms all over the world, studies have shown that ICT is underused (Mueller, Wood, Willoughby, Ross, \& Specht, 2008; Ruthven, 2009). In Serbia, one reason for the low ICT usage for teaching and learning is teachers' lack of sophisticated knowledge to support effective technology integration (Kadijevich, 2012). However, this situation is mitigated by younger teachers, who have demonstrated their attempts at teaching mathematics in primary and secondary schools in Serbia (Dimitrijević, Popović, \& Stanić, 2012).

Serbia is a south-eastern developing country in Europe with a population of 7.12 million. Free education is provided for children between ages 7 and 15 (grades 1-8) and those between ages 15 and 19 to attend elementary and secondary schools, respectively, although the latter is not compulsory by law. Depending on the grade level and subject, elementary and secondary school teachers receive their training at the relevant faculties in universities (UNESCO, 2011). All teachers have to complete their training in pedagogy and subject content at master's level before taking up appointments in schools. Among the goals of Serbian education are that students across all levels should be provided with opportunities to acquire high quality knowledge and skills and attitudes, including linguistic, mathematical, scientific, artistic, cultural, technical, and computer literacy skills necessary for life in modern society and develop the abilities to use ICT to find, analyse, utilise and communicate information. In 2010, the Serbian government initiated the Digital School 
Project with an aim to support the integration of technology in education through equipping elementary schools with computer labs for use in their studies, extracurricular activities, and free time. Costing about 15 million euros, the key outcomes of this project were to increase digital literacy, develop the e-skill set, and improve teaching and learning in the primary schools. As a result, 1,589 large elementary schools in Serbia were equipped with modern computer labs (5 to 30 seats), while 1,321 small schools in rural areas (with fewer than 40 students per school) were equipped with laptops and projectors (UNESCO, 2013).

In order to prepare future teachers as change agents to achieve educational goals, all teacher training providers (e.g., faculties of education) are required to offer at least one compulsory course for pre-service teachers to acquire necessary skills in ICT and provide professional development to support in-service teachers who are managing the computer laboratories. However, research indicates that the use of technology by teachers for teaching and learning is lacking and limited to low-level purposes. Dimitrijević et al. (2012) noted that the frequency of technology usage by mathematics teachers in Serbia for professional purposes is significantly lower than their technology usage for private purposes. In addition, technology is mainly used as digital storage. Among those who use technology for teaching, younger teachers display a higher level of aptitude and commitment to continuing education, factors which were found to have significant impacts on the use of technology in teaching and learning. The authors also claim that for effective integration of technology to take place in the curriculum, it is critical to ensure that pre-service teachers are well prepared prior to taking up teaching appointments.

\section{Literature review}

\section{Studies in technology acceptance}

Researchers interested in studying ICT usage in education have suggested low technology acceptance to be a key factor in explaining the under-utilisation by teachers (e.g., Hermans, 2008; Pierce \& Ball, 2009). Defined as using technology in the way it was designed to serve, technology acceptance research can shed light on the predictors of teachers' intention to use technology for teaching (Teo, 2009).

For a long time, technology acceptance researchers have situated their research in business contexts with the main purpose of understanding and predicting the user's intention to use technology. From their efforts, various models and theories have been proposed to examine the key determinants that influence users' intention to accept technology at their workplaces and for professional purposes. In recent years, researchers have found that the models and theories that emerged from the body of research within the business contexts could be applied to understanding technology acceptance in educational contexts (Teo, 2013). Among the most popular models in technology acceptance research, the technology acceptance model (TAM) (Davis, 1989) has been found to be a robust and parsimonious model for understanding the factors that affect users' intention to use technology in education (Teo, 2011, 2012).

\section{Research model}

Despite the popularity of the TAM as a framework to explain users' intention to use technology in education, there have been calls to extend and expand the model in order to increase its explanatory ability to address more sophisticated relationships in education involving variables external to the TAM (Hermans, 2008; Mumtaz, 2000). Various extended TAM models to explain pre-service and teachers' intention to use technology have been proposed and validated in the literature (e.g., Teo, 2009, 2010, 2011). In these, external variables have been adopted from other theories, such as the theory of planned behaviour (Ajzen, 1991), unified theory of acceptance and use of technology (Venkatesh, Morris, Davis, \& Davis, 2003), and pedagogical content knowledge (Shulman, 1986). For example, Pynoo et al. (2012) combined the TAM and the theory of planned behaviour to assess teachers' acceptance and use of a Belgian educational portal and found that all predictor variables, subjective norm, perceived usefulness, perceived ease of use, attitude towards computer use and perceived behavioural control were significant in explaining teachers' portal acceptance. Taking reference from the above-mentioned works, we synthetise the variables in the TAM and the theory of planned behaviour by including external variables such as subjective norm, content knowledge 
and facilitating conditions; factors which have been found to influence the core TAM variables (perceived usefulness, perceived ease of use, attitude towards computer use, and intention to use) to a significant degree.

\section{TAM hypotheses}

The TAM specifies the relationships among users' perceived usefulness, perceived ease of use, attitude towards computer use, and their intention to use technology. Intention to use technology is posited to be influenced by attitude towards use, as well as the direct and indirect effects of perceived usefulness and perceived ease of use. In addition, perceived usefulness and perceived ease of use jointly affect attitude towards use. Finally, perceived ease of use is hypothesised to have a direct effect on perceived usefulness. From the TAM, perceived usefulness refers to the degree to which a person believes that using a system would enhance his/her productivity while perceived ease of use has to do with the extent to which a person thinks that using a system will be relatively free of effort (Davis, 1989).

In building the model that predicts the level of technology acceptance of pre-service teachers in Singapore, Teo (2009) found, among other variables, that perceived usefulness and attitude towards use have a direct effect on pre-service teachers' intention to use technology, and perceived use of ease indirectly influences the behavioural intention through attitude and perceived usefulness. Chang, Yan, and Tseng (2012) provided evidence that perceived convenience, perceived ease of use and perceived usefulness have a significantly positive effect on attitude towards using; and perceived usefulness and attitude towards using have a significantly positive effect on continuance of intention to use English mobile learning among college students in Taiwan.

From the above, the following hypotheses were formulated:

H1: Pre-service teachers' perceived usefulness has a significant influence on their behavioural intention to use technology.

H2: Pre-service teachers' perceived usefulness has a significant influence on their attitude towards computer use.

H3: Pre-service teachers' attitude towards computer use has a significant influence on their behavioural intention to use technology.

H4: Pre-service teachers' perceived use of ease has a significant influence on their perceived usefulness.

H5: Pre-service teachers' perceived use of ease has a significant influence on their attitude towards computer use.

\section{Subjective norm}

Drawing on the theory of reasoned action, Fishbein and Ajzen (1975) defined subjective norm as the perceived pressures put onto a person to perform a given behaviour (or perform a task). In technology acceptance studies, subjective norm reflects a person's belief that people who are important or significant to him/her think he should or should not use technology. In other words, it is the degree to which a person perceives the demands of the important or "referent others" on that individual to use technology. To the sample in this study, treferent others may refer to their close peers, professors, and university institutional management. From the theory of planned behaviour (Ajzen, 1991) and unified theory of acceptance and use of technology (Venkatesh et al., 2003) subjective norm (or social influence) was hypothesised to have a direct effect on behavioural intention and perceived usefulness. Venkatesh and Davis (2000) argued that when a co-worker thought that the system was useful, a person was likely to have the same idea. In other words, individuals can choose to perform a specific behaviour even if they are not positive towards the behaviour or its consequences, depending on how important they think that the important referents believe that they should act in a certain way (Fishbein \& Ajzen 1975; Venkatesh \& Davis 2000). This was supported by Schepers and Wetzels (2007), who meta-analysed 88 studies on the relationship between subjective norm and the TAM constructs. They found overwhelming evidence that showed a significant relationship between subjective norm and perceived usefulness, and subjective norm and intention to use.

It is possible that individuals who perceive that others expect that they should use technology will have a high score on intentions to use technology. On examining pre-service teachers' attitudes to computer use with the 
extended TAM framework, Teo (2010) found significant influence of subjective norm on perceived usefulness of computers. Motaghian, Hassanzadeh, and Moghadam (2013) used an integrated model in order to assess instructors' adoption of web-based learning systems and found that subjective norm had a positive effect on perceived usefulness. Similarly, Park (2009) found that subjective norm was a significant factor in affecting university students' intention to use e-learning, in addition to other beliefs, such as perceived usefulness.

From the above, we formulated the following hypotheses concerning subjective norm and TAM variables in teaching mathematics with the use of computers:

H6: Pre-service teachers' subjective norm has a significant influence on their perceived usefulness.

H7: Pre-service teachers' subjective norm has a significant influence on their behavioural intention to use technology.

\section{Content knowledge}

Shulman (1986) proposed the pedagogical content knowledge framework to explain teachers' subject matter knowledge and the role it plays in teaching. This was later expanded by Mishra and Koehler (2006) to include technological knowledge, in addition to content knowledge and pedagogical knowledge. Teachers who are high on content knowledge are generally accepting of new ideas and pedagogical conceptions in innovation programs, such as the use of technologies for teaching and learning (Lloyd \& Wilson, 1998). Research evidence indicates that mathematical content knowledge is important to the effective use of technology in mathematics teaching (Crisan, 2001). In a review of the literature, Lagrange (1999) suggested that mathematical knowledge and conceptualisation are dependent on new techniques such as using new tools or teaching in a new environment. A study by Dimitrijević et al. (2012) found one of the main predictors of teachers' usage of computers in mathematics teaching in Serbia to be their perceived level of mathematical knowledge, that is, their average marks during the study, and that teachers with strong academic mathematics background were more likely to use technology in their teaching practice. Content knowledge, as a generic part of technological pedagogical content knowledge, could play a very important role in teachers' intention to use technology in teaching mathematics (Wachira \& Keengwe, 2011).

Therefore, we formulated the following hypotheses for this study:

H8: Pre-service teachers' knowledge of mathematics has a significant influence on their behavioural intention to use technology.

H9: Pre-service teachers' knowledge of mathematics has a significant influence on their perceived ease of use.

\section{Facilitating conditions}

Facilitating conditions are factors in the environment that influence a person's desire to perform a task. These may include technical support, skills training, and access to information or resources (Groves \& Zemel, 2000). It is also a construct that reflects an individual's perceptions about his/her control over a behaviour. Taylor and Todd (1995) underscored that external control, as part of perceived behavioural control, is conceptualised as the individual perception of technology and resource-facilitating conditions. This was supported by Venkatesh (2000), who found that an individual's general perception of technology and resource-facilitating conditions could be a significant influence on perceived ease of use.

Among teachers, Lim and Khine (2006) revealed that poor facilitating conditions (e.g., lack of access to computers, inadequate technical support given to teachers) act as barriers to ICT integration in the classroom. On its relationship to the TAM constructs, facilitating conditions were found to be significantly related to attitudes towards computer use (Teo et al., 2012). In their studies on pre-service teachers, Teo, Ursavas, and Bahcekapili (2012) found that facilitating conditions have a direct influence on perceived ease of use and perceived usefulness. It is possible that when the participants feel supported in ways that are important to them, they perceive technology to be easy to use. Among the facilitating conditions, technical support was ranked highly on the list of factors that affect teachers' implementation technology. From their study, Groves 
and Zemel (2000) suggested that technical support generally includes the provision of help desks, hotlines, and online support services. In addition, participants may have inferred from the presence (or lack) of technical support in an organisation that technology is useful to them (Teo, 2009).

From the above review of the literature, the following hypotheses were formulated for this study:

H10: Facilitating conditions have a significant influence on pre-service teachers' attitude towards computer use.

H11: Facilitating conditions have a significant influence on pre-service teachers' perceived ease of use.

H12: Facilitating conditions have a significant influence on pre-service teachers' perceived usefulness.

In this study, intention to use technology was used as the dependent variable because of its close link to actual behaviour (Hu, Clark, \& Ma, 2003; Kiraz \& Ozdemir, 2006). Behavioural intention indicates how hard people are willing to try to perform a behaviour (Ajzen, 1991). In their review of 79 empirical studies, Turner, Kitchenham, Brereton, Charters, and Budgen (2010) found evidence for the positive relationship between intention to use and actual use of technology, and this lends support for the use of intention to use as an outcome variable in this study to predict pre-service teachers' future technology usage behaviours.

From the above hypotheses a research model is proposed (Figure 1). This model hypothesises that pre-service teachers' intention to use technology to teach mathematics can be predicted and explained by a subjective perception of usefulness, attitudes towards computer use, knowledge of mathematics, and subjective norm, in conjunction with the indirect influence of facilitating conditions and ease of use.

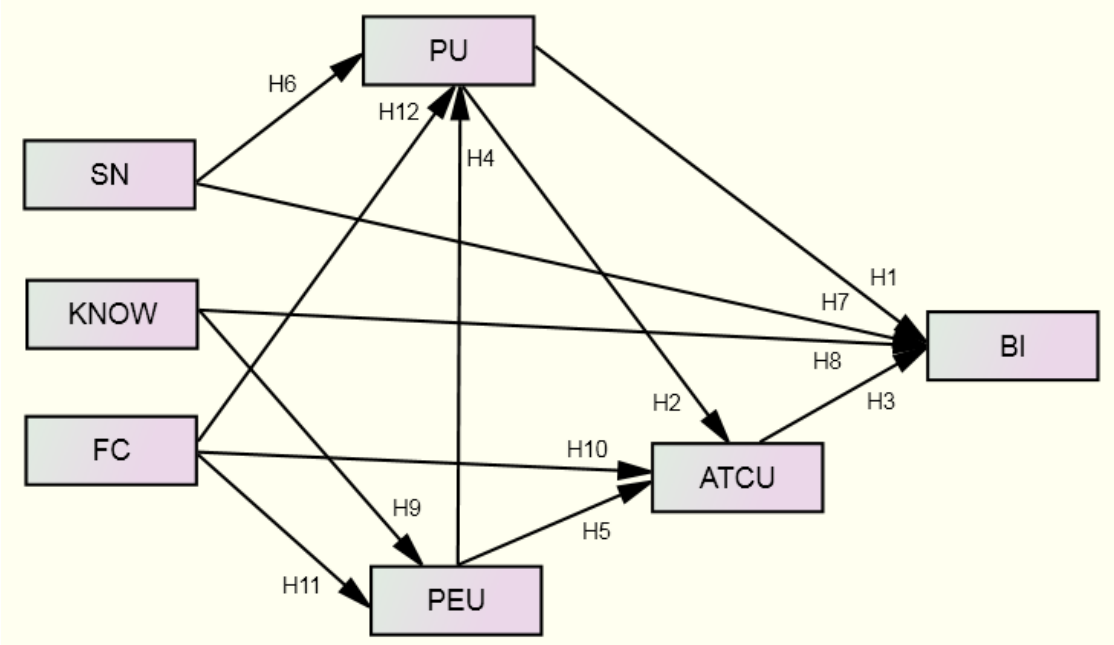

Figure 1. Research model

Notes. SN: subjective norm; KNOW: perceived mathematical knowledge; FC: facilitating conditions; PU: perceived usefulness; PEU: perceived ease of use; ATCU: attitude towards computer use; BI: behavioural intention to use technology.

\section{Aims of this study}

The purpose of this study is to examine the variables that have significant influence on the intention to use technology in teaching mathematics (i.e., behavioural intention) among pre-service teachers in Serbia. This study has the potential to contribute to existing debates on the relevance of the TAM as a framework to explain and predict technology usage in a teacher education context. By applying an extended TAM with a non-Western culture, the findings from this study allow researchers to assess its validity and robustness across cultures. This study could serve to inform teacher education instructors and administrators on the variables that directly impact on pre-service teachers' intention to use technology in their future jobs. Being guided by 
the findings of this study, pre-service teachers could be led to strengthen their intention to use technology in their capacity as future mathematics teachers. Two research questions guide this study:

(1) To what extent does the research model adequately explain pre-service teachers' intention to use technology in teaching mathematics?

(2) Are there significant differences in gender and age that influence pre-service teachers' intention to use technology in teaching mathematics?

\section{Method}

\section{Participants}

Participants were 313 pre-service teachers recruited from two universities in Serbia who have completed classes in technology, teaching of mathematics, and mathematics. Of these, there were 277 female (88.5\%) participants, and the mean age was $22.44(S D=1.22)$ years old. The participants in this study represented about $60 \%$ of the pre-service teacher population in the two universities. Among the participants, 188 (60.1\%) were in the third year of their study, and the others were in year four.

\section{Procedure}

Researchers have suggested that viewing videos helps teachers to focus their attention on important aspects of teaching and learning (Lampert \& Ball, 1998; Star \& Strickland, 2007). Given that pre-service teachers in Serbia have limited use of computers in teaching mathematics due to the varying availability of computer equipment in primary schools, the authors developed a 6-minute-long video stimulus (Figure 2) in order to help the participants to focus on the technology when they responded to the survey. The video contains short teaching clips that illustrate three different types of computer applications in the teaching of mathematics. After viewing the video, participants completed a survey questionnaire, and on average each tool took not more than 20 minutes to do so. Participants did not receive any reward in monies or in kind.

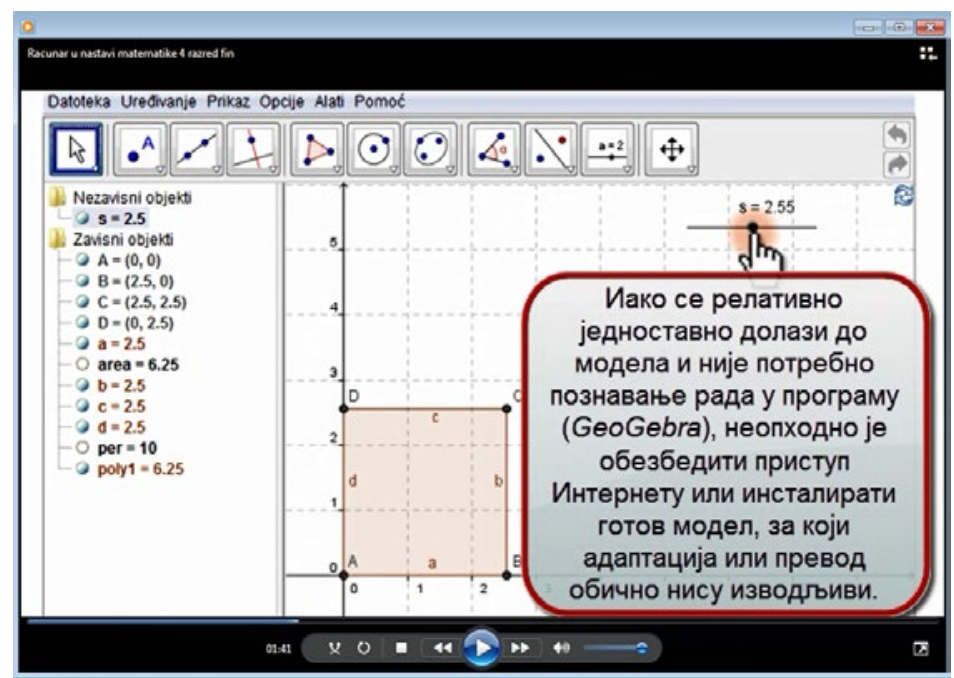

Figure 2. Screenshot of video stimulus

\section{Instrument}

A survey questionnaire was employed in this study. In addition to the questions on demographics, items were compiled to assess participants' responses in order to measure the variables in the research model. We adapted them from various published sources and translated them into the Serbian language. These are perceived usefulness (4 items), perceived ease of use (4 items), attitude towards computer use (4 items), behavioural 
intention to use technology (3 items), subjective norm (3 items), perceived mathematical knowledge (3 items), and facilitating conditions (2 items). Each item was measured on a 5-point Likert scale with 1 = strongly disagree and 5 = strongly agree.

\section{Survey translation}

To ensure the validity of the instrument, each item underwent the process of translation and countertranslation. The original survey was translated by the second author from English into Serbian. Next, the Serbian version of the survey was translated into English by a professional translator. The two versions, original and translated, were compared, and the changes were made to the Serbian version by a faculty member who worked as an English language teacher assistant to ensure that the meaning and intent of each item were kept intact.

\section{Data analysis}

Data were analysed using the structural equation modelling (SEM) approach. The analysis involves testing for data normality and the research model (representing the relationships among the seven variables in this study: behavioural intention to use, perceived usefulness, perceived ease of use, attitudes towards computer use, subjective norm, perceived mathematical knowledge, and facilitating conditions). In the research model, all free parameters were estimated and evaluated for statistical significance. SEM was employed for its ability to analyse the relationships between latent and observed variables and estimate random errors in the observed variables directly, giving rise to more precise measurements of the items and constructs in the survey. Because of the shift from the items to the constructs, SEM has an added advantage over traditional data analysis techniques in its ability to model the relationships among latent variables and be more aligned with how hypotheses are expressed conceptually and statistically (Hoyle, 2011). Using the standard two-step approach to SEM (Schumacker \& Lomax, 2010), the first step involves estimating the measurement model (confirmatory factor analysis - CFA model) for all latent variables in the model. The measurement model describes how well the observed indicators (survey items) measure the unobserved (latent) constructs. In the second step, the structural part of the SEM is estimated. This part specifies the relationships among the exogenous and endogenous latent variables. To obtain reliable results in SEM, researchers recommend a sample size of 100 to 150 cases (e.g., Kline, 2010). Researchers also recommend the Hoelter's critical N, which refers to the sample size for which one would accept the hypothesis that the proposed research model is correct at the .05 level of significance. The Hoelter's critical $\mathrm{N}$ for the model in this study is 202 and, given that the sample size of this study is 313, SEM is regarded as an appropriate technique for data analysis.

\section{Results}

\section{Descriptive statistics}

All 23 items measuring the seven constructs in the questionnaire were examined for their mean, standard deviation, skewness, and kurtosis. All means scores were above the mid-point of 3.0 and they indicate an overall positive response to the constructs in the model. The standard deviations reflect a fairly narrow spread of participants' responses, ranging from .73 to 1.19. Skewness and kurtosis indices were small and well within the accepted level of | 3 | and | 10 | respectively (Kline, 2010). On the recommendations from Kline (2010), the data in this study were considered to be univariate normal.

\section{Evaluation of the measurement model}

The measurement model was assessed using CFA and conducted with Amos 7.0 using the maximum likelihood estimation (MLE) procedure. The MLE is a popular and robust procedure for use in SEM (Schumacker \& Lomax, 2010). As the MLE procedure assumes multivariate normality of the observed variables, the data in this study were examined using Mardia's normalised multivariate kurtosis value. Mardia's (1970) coefficient for the data in this study was 157.49, which is lower than the value of 575 computed based on the formula $p(p+2)$ where $p$ equals the number of observed variables in the model (Raykov \& Marcoulides, 2008). On this basis, multivariate normality of the data in this study was assumed. The results of the CFA are shown in Table 1. 
All parameter estimates were significant at the $p<.01$ level, as indicated by the $t$-value (greater than 1.96). The standardised estimates ranged from .56 to .90 , and these were regarded as acceptable (Hair, Black, Babin, \& Anderson, 2010). The internal consistency (alpha) of all constructs range from .64 to .87. Finally, the measurement model fit was assessed using a number of fit indices: $\chi^{2}, \chi^{2} / \mathrm{df}$, Tucker-Lewis index (TLI), comparative fit index (CFI), root mean squared error of approximation (RMSEA), and standardised root mean residual (SRMR). The model has a good model fit $\left[\chi^{2}=445.240 ; \chi^{2} / \mathrm{df}=3.00\right.$; TLI $=.974$; CFI $=.980$; RMSEA $=.058$; SRMR $=.027]$. The adequacy of the measurement model indicates that all items were reliable indicators of the hypothesised constructs they were purported to measure.

Table 1

Results for the measurement model

\begin{tabular}{|c|c|c|c|c|c|c|}
\hline Item & UE & $t$-value & SE & $\operatorname{AVE}(>.50)^{*}$ & $\begin{array}{l}\text { Composite } \\
\text { reliability }\end{array}$ & $\begin{array}{c}\text { Cronbach's } \\
\text { alpha }\end{array}$ \\
\hline PU1 & 1.139 & 11.424 & .745 & .64 & .77 & .87 \\
\hline PU2 & 1.445 & 13.161 & .903 & & & \\
\hline PU3 & 1.445 & 12.975 & .881 & & & \\
\hline PU4 & 1.000 & --- & .653 & & & \\
\hline PEU1 & .738 & 10.804 & .634 & .57 & .63 & .84 \\
\hline PEU2 & 1.044 & 13.294 & .773 & & & \\
\hline PEU3 & 1.114 & 14.284 & .838 & & & \\
\hline PEU4 & 1.000 & --- & .761 & & & \\
\hline ATCU1 & .756 & 12.257 & .693 & .61 & .68 & 87 \\
\hline ATCU2 & .890 & 14.709 & .804 & & & \\
\hline ATCU3 & .998 & 15.399 & .834 & & & \\
\hline ATCU4 & 1.000 & --- & .789 & & & \\
\hline BI1 & 1.000 & --- & .829 & .46 & .48 & .69 \\
\hline BI2 & .650 & 7.962 & 610 & & & \\
\hline BI3 & .668 & 7.670 & .568 & & & \\
\hline SN1 & 1.244 & 8.151 & .816 & .47 & .43 & .72 \\
\hline SN2 & .854 & 8.078 & .621 & & & \\
\hline SN3 & 1.000 & --- & 610 & & & \\
\hline KNOW1 & 1.219 & 12.987 & .859 & .66 & .73 & .85 \\
\hline KNOW2 & 1.287 & 12.999 & .865 & & & \\
\hline KNOW3 & 1.000 & --- & .697 & & & \\
\hline FC1 & 1.000 & --- & .856 & .52 & .44 & .64 \\
\hline FC2 & .635 & 3.757 & .555 & & & \\
\hline
\end{tabular}

Notes. UE: unstandardised estimate; SE: standardised estimate.

* indicates an acceptable level

--- This value was fixed at 1.00 for model identification purposes.

AVE: average variance extracted. This is computed by adding the squared standardised factor loadings divided by number of factors of the underlying construct.

CR: composite reliability. This is computed by the sum of squared standardised factor loadings divided by the sum of squared standardised factor loadings and the sum of the error variance.

PU: perceived usefulness; PEU: perceived ease of use; ATCU: attitude towards computer use; BI: behavioural intention to use technology; SN: subjective norm; KNOW: perceived mathematical knowledge; FC: facilitating conditions.

\section{Evaluation of the structural model}

In evaluating the structural model, researchers recommend the use of several goodness-of-fit indices to assess the match between any particular model and the data (Klem, 2000; Kline, 2010; McDonald \& Ho, 2002; Schumacker \& Lomax, 2010). In addition to using the chi-square test, which is highly sensitive to sample size, the ratio of the chi-square to its degrees of freedom was computed when deciding on model fit. 
Following the recommendations by $\mathrm{Hu}$ and Bentler (1999), RMSEA and SRMR were used as measures of absolute fit, and the CFI and TLI were used as indices of incremental fit. From the literature (e.g., Hair et al., 2010), values of .90 or more for the CFI and TLI, and values of .05 and .08 or less for RMSEA and SRMR, respectively, are reflective of a good fit. From the results, the structural model has a good fit $\left[\chi^{2}=6.226 ; \chi^{2} / \mathrm{df}\right.$ $=1.567 ; \mathrm{TLI}=.969 ; \mathrm{CFI}=.994 ; \mathrm{RMSEA}=.043 ; \mathrm{SRMR}=.023]$. Figure 3 shows the standardised path coefficients of the research model.

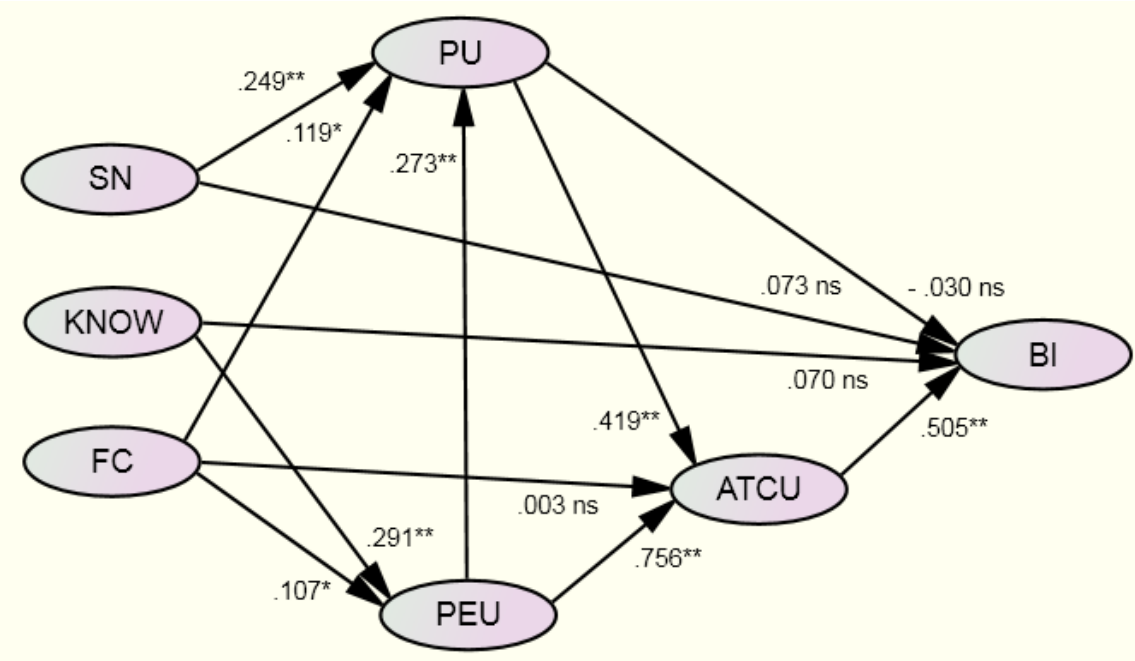

Figure 3. Standardised path coefficients of the research model $* p<.05 ; * * p<.001$; ns: non-significant Notes. PU: perceived usefulness; SN: subjective norm; KNOW: perceived mathematical knowledge; FC: facilitating conditions; PEU: perceived ease of use; ATCU: attitude towards computer use; BI: behavioural intention to use technology.

\section{Tests of hypotheses}

Overall, eight out of twelve hypotheses were supported by the data. Except for H1, all hypotheses (H2 to H5) pertaining to the relationship among the variables from the core TAM were supported in this study. Of the hypotheses related to the variables external to the TAM, four were supported (H6, H9, H11, and H12) and three were not (H7, H8, and H10). Four endogenous variables (behavioural intention to use technology, attitudes towards computer use, perceived usefulness, and perceived ease of use) were tested in the research model (Figure 1). Overall, the variance in attitude towards computer use was highest with an $R^{2}=0.409$. This means that together, perceived usefulness, facilitating conditions, and perceived ease of use accounted for $40.9 \%$ of the variance in attitudes towards computer use. Next, the variance in perceived ease of use and perceived usefulness were explained by their antecedents at amounts of $17.8 \%$ and $10.6 \%$, respectively. Finally, the dependent variable in this study, behavioural intention to use technology, was explained by perceived usefulness, attitude towards use, subjective norm, and facilitating conditions with an $R^{2}$ of 0.054 . This means that, together, these four variables accounted for only $5.4 \%$ of the variance found in the behavioural intention to use technology. A summary of the hypotheses testing results is shown in Table 2 . 
Table 2

Hypothesis testing results

\begin{tabular}{|c|c|c|c|c|}
\hline Hypotheses & Path & Path coefficient & $t$ - value & Results \\
\hline $\mathrm{H}_{1}$ & $\mathrm{PU} \rightarrow \mathrm{BI}$ & -.036 & $-.309 \mathrm{~ns}$ & Not supported \\
\hline $\mathrm{H}_{2}$ & $\mathrm{PU} \rightarrow \mathrm{ATCU}$ & .479 & $9.981 * *$ & Supported \\
\hline $\mathrm{H}_{3}$ & $\mathrm{ATCU} \rightarrow \mathrm{BI}$ & .532 & $3.508 * *$ & Supported \\
\hline $\mathrm{H}_{4}$ & $\mathrm{PEU} \rightarrow \mathrm{PU}$ & .238 & $5.249 * *$ & Supported \\
\hline $\mathrm{H}_{5}$ & $\mathrm{PEU} \rightarrow \mathrm{ATCU}$ & .753 & $4.995 * *$ & Supported \\
\hline $\mathrm{H}_{6}$ & $\mathrm{SN} \rightarrow \mathrm{PU}$ & .181 & $4.748 * *$ & Supported \\
\hline $\mathrm{H}_{7}$ & $\mathrm{SN} \rightarrow \mathrm{BI}$ & .064 & $1.330 \mathrm{~ns}$ & Not supported \\
\hline $\mathrm{H}_{8}$ & $\mathrm{KNOW} \rightarrow \mathrm{BI}$ & .072 & 1.087 n.s. & Not supported \\
\hline $\mathrm{H}_{9}$ & $\mathrm{KNOW} \rightarrow \mathrm{PEU}$ & .285 & $5.404 * *$ & Supported \\
\hline $\mathrm{H}_{10}$ & $\mathrm{FC} \rightarrow \mathrm{ATCU}$ & .002 & .073 n.s. & Not supported \\
\hline $\mathrm{H}_{11}$ & $\mathrm{FC} \rightarrow \mathrm{PEU}$ & .085 & $2.208 *$ & Supported \\
\hline $\mathrm{H}_{12}$ & $\mathrm{FC} \rightarrow \mathrm{PU}$ & .067 & $2.023^{*}$ & Supported \\
\hline
\end{tabular}

Notes. PU: perceived usefulness; BI: behavioural intention to use technology; ATCU: attitude towards computer use; PEU: perceived ease of use.

\section{MIMIC modelling}

In this study, multiple indicators, multiple causes (MIMIC) modelling was used to assess if there are significant differences in the behavioural intention to use technology by participants' gender and age. MIMIC modelling is used when it is believed that the observed variables are manifestations of an underlying unobserved latent variable that can be affected by other exogenous variables (causes) that influence the latent factor (Joreskog \& Goldberger, 1975). Although group comparisons (e.g., between male and female) are typically made using the traditional $t$-test, MIMIC modelling is employed in this study because first, it allows simultaneous analysis of a model with latent variables and observed indicators, and second, measurement error is modelled and computed to facilitate a more precise estimation of item reliability. A further advantage of MIMIC modelling is that it allows for a dichotomous group comparison to be made (e.g., gender) using cause indicators as exogenous variables. This is often used as an alternative to multiple-group comparisons where bigger sample sizes are required (Brown, 2006). Through specification of a MIMIC model, one could estimate group differences on latent variables factors on the total sample. Thus, for the MIMIC analysis, the sample is not partitioned into subsamples, and there are no special identification requirements beyond the usual ones for single-sample analyses (Kline, 2010).

The MIMIC modelling process is a special case of SEM and involves an estimation of the measurement part (that displays the causal link among the latent variables and the observed causes) and the structural part (which shows how the latent variables are estimated through the observed variables or indicators). The MIMIC model incorporates additional variables, which are assumed to influence the latent factors and also allows the testing of hypothesis on direction of effects between different factors. The MIMIC model has an opposite layout from a path model in that the dichotomous variable (or dependent variable) is represented at the left side instead of the right side of the model.

The simplest form of MIMIC model involves a single unobserved latent variable “caused” by several observed variables and indicated by several observed exogenous variables (Jöreskog \& Sörbom, 1996, p. 185). The observed exogenous variables in this study that are assumed to explain the latent variable behavioural intention to use technology (caused by the observed variables perceived usefulness, perceived ease of use, attitude towards compute use, subjective norm, perceived mathematical knowledge, and facilitating conditions) are gender and age. This part of the model can be viewed as six multiple regressions: perceived usefulness, perceived ease of use, attitude towards compute use, subjective norm, perceived mathematical knowledge, and facilitating conditions on gender and age. For example, if gender is coded such that males are 0 and females 1 , a negative coefficient for the regression of perceived usefulness on gender would indicate that females have a lower level of perceived usefulness than males. Hence, there are multiple 
indicators, which reflect the underlying factors, and multiple causes, which affect the underlying factors. For the purpose of dichotomising the gender and age in this study, gender was coded such that males were 0 and females 1 , and the median age (22 years) was used and denoted by 0 and 1 to represent the younger and older participants, respectively. The modelling process in this study follows established procedures recommended by Kline (2010). Figure 4 shows the MIMIC model that represents the effects of gender and age, which are represented by arrows from these variables to the latent variable (behavioural intention to use technology). This is the structural part of the MIMIC model that uses the observed dichotomous variables to predict a latent variable. On the other hand, the latent variable has arrows pointing out to the observed indicator variables (perceived usefulness, perceived ease of use, attitude towards compute use, subjective norm, perceived mathematical knowledge, and facilitating conditions) and is explained by them. This is the measurement part of the MIMIC model that defines the latent variable. The path coefficients for the direct effects of the gender and age variables will provide information about whether the differences between males and females or younger and older participants predict the variable behavioural intention to use technology.

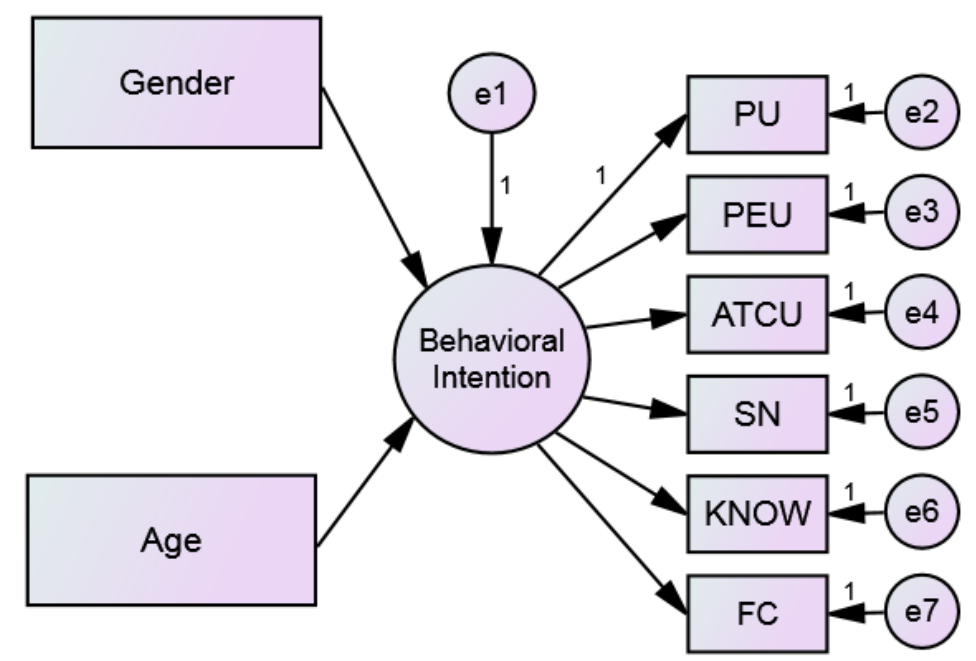

Figure 4. MIMIC model with gender and age as causes

Notes. PU: perceived usefulness; PEU: perceived ease of use; ATCU: attitude towards computer use; SN: subjective norm; KNOW: perceived mathematical knowledge; FC: facilitating conditions.

The fit of the MIMIC model was estimated using the MLE procedure and assessed using a number of fit indices representing the absolute and incremental aspects of model fit (Hair et al., 2010). They were $\chi^{2}, \chi^{2} / \mathrm{df}$, TLI, CFI, RMSEA and SRMR. To achieve an acceptable model fit, the $\chi^{2} / \mathrm{df}$ ratio should be less or equal to 3.0 while the TLI and CFI should be equal or greater than .90. The RMSEA and SRMR should be equal or smaller than .05 and .08, respectively (Hair et al., 2010).

The fit of this model was good $\left(\chi^{2}=26.994, d f=17, p=.058, \chi^{2} / d f=1.588\right.$, TLI $=.95$, CFI $=.97$, RMSEA $=.043[\mathrm{CI}=.000, .073]$, SRMR $=.04)$. The item parameter estimates reveal that all exogenous variables in the MIMIC model were significant in explaining behavioural intention to use technology (PU: $\beta=.607$, PEU: $\beta=.608$, ATCU: $\beta=.942$, SN: $\beta=.242$, KNOW: $\beta=.361$, and FC: $\beta=.219$ ). The regression part (left side) of the model shows that no differences were found in behavioural intention to use technology by gender $(\beta$ $=.012 ; p>.05)$ and age $(\beta=.023 ; p>.05)$ although the influence by age on behavioural intention to use technology was stronger than that by gender. Table 3 summarises the results of the MIMIC modelling. 
Table 3

MIMIC modelling results

\begin{tabular}{lcc}
\hline Path & Path coefficient & Results \\
\hline $\mathrm{BI} \rightarrow$ PU & .607 & $* *$ \\
$\mathrm{BI} \rightarrow$ PEU & .608 & $* *$ \\
$\mathrm{BI} \rightarrow$ ATCU & .942 & $* *$ \\
$\mathrm{BI} \rightarrow$ SN & .242 & $* *$ \\
$\mathrm{BI} \rightarrow$ KNOW & .361 & $* *$ \\
$\mathrm{BI} \rightarrow$ FC & .219 & $\mathrm{~ns}$ \\
Gender & .012 & $\mathrm{~ns}$ \\
Age & .023 & \\
\hline
\end{tabular}

$* * p<.001 ;$ ns: non-significant.

Notes. BI: behavioural intention to use technology; PU: perceived usefulness; PEU: perceived ease of use; ATCU: attitude towards computer use; SN: subjective norm; KNOW: perceived mathematical knowledge; FC: facilitating conditions.

\section{Discussion}

This study aims to develop and test a model to explain the behavioural intention to use technology in mathematics teaching among pre-service teachers in Serbia. Using SEM, the results indicate that the model is an adequate fit to the data collected in this study.

\section{Antecedents of behavioural intention}

This study shows that attitudes towards computer use have a direct positive effect on the behavioural intention to use technology, suggesting that pre-service teachers with positive feelings towards the use of computers are likely to use computers to teach mathematics. This finding is consistent with recent studies that examined the influence of attitudes towards computer use among pre-service teachers in other countries (Teo, 2009, 2011; Yuen \& Ma, 2008). In addition, the results show that attitudes towards computer use had mediated the effect of perceived usefulness and perceived ease of use on behavioural intention to use technology. It is likely that the pre-service teachers in this study would not use technology to teach mathematics simply because they perceived it to be free of effort or useful; they had to have a positive attitude towards computer use as well. This mediating influence of attitudes towards computer use for perceived usefulness and perceived ease of use on behavioural intention to use technology is illustrated by the lack of support for hypothesis 1 and support for hypotheses 2 and 5.

The lack of significant influence found for perceived usefulness on behavioural intention to use technology in this study was not aligned with research on the TAM. It is possible that perceived usefulness alone was not a sufficiently strong driver for pre-service teachers to use technology to teach mathematics and that the nature of mathematics teaching was perceived to be relatively complex so that other variables such as perceived ease of use and attitudes towards computer use have to be present to have a significant influence on their behavioural intention to use technology.

This study found that subjective norm had a significant influence on perceived usefulness but did not affect behavioural intention to use technology, suggesting that even if pre-service teachers held the impression that people important to them would support the use of technology for teaching mathematics, they would consider technology to be useful but this would not influence their behavioural intention to use technology significantly. This finding is consistent with Teo (2011) and Motaghian et al. (2013) who found that subjective norm did not influence teachers and instructors' intention to use technology for teaching and using web-based learning systems respectively. These authors opined that pre-service and practising teachers were able to exercise greater volition than their counterparts in business and industrial contexts on when and how they use technology at the workplace. 
The results also show that facilitating conditions have a significant influence on pre-service teachers' perceived usefulness and perceived ease of use but not on attitudes towards computer use. Although pre-service teachers may perceive technology to be useful and easy to use in the presence of technical support, their attitude towards computers would not necessarily be influenced (Teo et al., 2012). However, in their study on students' use of technology for learning, Lai, Wang, and Lei (2012) found that, in addition to FC having a significant influence on perceived usefulness and perceived ease of use, facilitating conditions also had a significant effect on attitudes towards computer use. This finding suggests that the pre-service teachers in this study were driven by their affect (attitudes towards computer use) more than their environment and perceptions of support.

This study found a significant influence on perceived ease of use by the knowledge of mathematics variable although the latter did not influence behavioural intention to use technology in a significant way. When pre-service teachers perceive their knowledge of mathematics to be high, they would perceive the use of technology to be relatively free of effort although this did not mean they would use it for teaching mathematics. However, the results suggest that if we consider attitudes towards computer use with perceived mathematical knowledge and perceived ease of use, pre-service teachers' behavioural intention to use technology would be heightened.

\section{MIMIC modelling}

Using MIMIC modeling, this study found no significant differences in behavioural intention to use technology for gender and age. These findings are consistent with research that supported the lack of gender and age difference in pre-service teachers and students' acceptance of technology for teaching and learning (Ong \& Lai, 2006; Pan \& Jordan-Marsh, 2010; Teo, Luan, Thammetar, \& Chattiwat, 2011). The lack of gender difference may be attributed to the global trend where males and females in all socieites are provided equal opportunities to be exposed and have access to technology for learning (Mayer-Smith, Pedretti, \& Woodrow, 2000). In the case of the pre-service teachers in this study, the lack of gender difference may be a positive outcome of the Serbian education framework where, among the goals, all students are provided with opportunities to acquire the computer literacy skills necessary for life in modern society and develop the abilities to use ICT to find, analyse, utilise and communicate information (UNESCO, 2013).

The lack of age difference is consistent with the relative youth of the sample in this study (22.44 years old, $S D$ $=1.22$ ). This is also consistent with a study by Dimitrijevic et al. (2012) who suggested that younger teachers in Serbia were more inclined to engage with technology for instructional purposes. In addition, the pre-service teachers in this study are completing undergraduate degrees in a teacher education program where technology is integrated into their courses in pedagogy and subject disciplines. It was thought that this shared experience in technology and the academic background with technology among the participants in this study are the main reasons for the lack of age difference in the intention to use technology for teaching mathematics.

\section{Limitations of the study}

The data provided empirical support to the selected six variables that were capable of explaining only $5.4 \%$ of the variance in behavioural intention. This leads to the conclusion that some other variables that may significantly impact on the acceptance of technology in mathematics teaching were excluded. There is a possibility that other variables not included in the TAM may influence pre-service teachers' intention to use technology in teaching mathematics in a significant way.

Although all methodology precautions were undertaken, there are limitations. Firstly, data were collected through self-reports, which have their own benefits but may lead to the common method variance and thus may inflate the true relationships between variables. Secondly, the use of student teachers as a sample instead of practising teachers may not represent the true picture because of their lack of experience in practice and stress involved in integrating computers in the actual teaching process. There is a possibility that other significant variables have been overlooked and excluded. 
It is possible that other sociocultural variables may influence pre-service teachers' intention to use technology in teaching mathematics. For example, while teachers appeared to recognise the pervasive nature of technology and declare their support for the use of technology in instruction, it has been found that they prefer the traditional teaching style, as it is a familiar and tested way of teaching (Mumtaz, 2000). Cuban (1993) claimed that the cultural beliefs (about what teaching is, how learning occurs, what knowledge is proper in school) in schools support student-teacher but not student-machine relationships. Consequently, schools seem to be slow in embracing technology and resistant to change. At the same time, teachers' beliefs about the benefits of students' learning with technology is an important factor to achieving educational outcomes, since the opportunity to interact with technology in the mathematics classrooms has been found to increase students' motivation and enjoyment (Bennison \& Goos, 2010; Pierce \& Ball, 2009). Finally, because only pre-service teachers training to teach mathematics were used in this study, they may have responded according to the subject-specific nature of technology use, hence limiting the generalisability of the findings of this study to teachers or pre-service of other subjects.

In this paper, the use of presentations and simulation models in teaching mathematics were examined. Technology is an umbrella concept that may involve many tools such as information exchange, development of group projects in a wiki environment, knowledge testing, making new models (e.g., with GeoGebra), use of computer-intensive algebra, computer-assisted instructions, spreadsheets and dynamic geometry software, interactive tutorials, hypermedia, simulations and educational games. Since each of those tools marks its own presence in the adoption of technology in teaching mathematics, future studies should include a wider range of technology use in the model.

Future research could include study among practising teachers of different subjects and examination of other variables of interest to the mathematics education community and ways of extension the TAM at various levels of technology acceptance.

\section{Implications for practice}

This study should help policy makers and managers at educational institutions (particularly in Serbia) to pay special attention to factors that have a determining role in improving pre-service teachers' acceptance of technology in the teaching of mathematics. If teacher educators want to motivate student teachers to use computers in teaching, they need to make sure that they have enough opportunities and adequate courses to acquire the basic skills necessary for the integration of computers into such ways of teaching and learning, and to start to perceive them as easy to use. There should also be a conscious effort in creating a conducive learning environment where pre-service teachers can gain successful experiences in harnessing technology for teaching and learning. It is reasonable to expect a successful experience with technology to foster the development of positive attitudes towards computer use among pre-service teachers, and this in turn would significantly impact on their intention to use technology.

On their part, teacher educators could model the integration of technology through their lesson delivery and assessment design. By modelling the use of technology, teacher educators may act as facilitators to shape pre-service teachers' perceived usefulness and perceived ease of use of technology. Because of their status in the institutions, these educators act as referent others for their students whose subjective norm may be influenced positively. From this study, perceived usefulness, perceived ease of use and subjective norm are important constructs that shape pre-service teachers' intention to use technology.

\section{Conclusion}

This study examined the variables that influence the intention to use technology in teaching mathematics among pre-service teachers in Serbia. The TAM was extended by three external variables to explain the intention to use technology among the participants. Attitude was found to be the only construct with a significant influence on behavioural intention. It also mediates perceived usefulness and perceived ease of use in explaining behavioural intention to use technology. Subjective norm, facilitating conditions and knowledge of mathematics, also influenced behavioural intention indirectly through perceived usefulness, perceived ease 
of use, and attitude towards computer use. Finally, no significant differences were found in the pre-service teachers' intention to use technology in teaching mathematics by their gender and age. Given a dearth of research of this nature in Serbia, this study serves as a starting point in understanding pre-service teachers' intentions to use technology to teach mathematics. From a theoretical perspective, this study contributes to enhancing the debates around technology acceptance for teaching specific subjects (e.g., mathematics) and among users in cultures that do not have the same level of technological advancements from the studies that are widely reported in the literature.

\section{References}

Ajzen, I. (1991). The theory of planned behavior. Organizational Behavior and Human Decision Processes, 50, 179-211. doi:10.1016/0749-5978(91)90020-T

Anderson, R. (2008). Implications of the information and knowledge society for education. In J. Voogt \& G. Knezek (Eds.), International handbook of information technology in primary and secondary education (pp. 5-22). NewYork, NY: Springer.

Bennison, A., \& Goos, M. (2010). Learning to teach mathematics with technology: A survey of professional development needs, experiences and impacts. Mathematics Education Research Journal, 22(1), 31-56. doi:10.1007/BF03217558

Brown, T. (2006). Confirmatory factor analysis for applied research. New York, NY: Guildford Press.

Chang, C. C., Yan, C. F., \& Tseng, J. S. (2012). Perceived convenience in an extended technology acceptance model: Mobile technology and English learning for college students. Australasian Journal of Educational Technology, 28(5), 809-826. Retrieved from http://ascilite.org.au/ajet/submission/index.php/AJET/article/view/818

Crisan, C. (2001). The interaction between the use of ICT and Mathematics teachers' professional knowledge base for teaching. Research in Mathematics Education, 3(1), 87-100. doi:10.1080/14794800008520086

Cuban, L. (1993). Computers meet classrooms: Classroom wins. Teachers College Record, 95(2), 185-210. Retrived from http://www.tcrecord.org/content.asp?contentid=82

Davis, F. D. (1989). Perceived usefulness, perceived ease of use, and user acceptance of information technology. MIS Quarterly, 13(3), 319-340. Retrieved from http://misq.org/perceived-usefulness-perceived-ease-of-use-and-user-acceptance-of-information-technolo gy.html

Dimitrijević, S., Popović, B., \& Stanić, M. (2012). Computer use in mathematics teaching - overview of the situation in Serbia. Croatian Journal of Education, 14, 387-415. Retrieved from http://hrcak.srce.hr/index.php?show=clanak\&id_clanak_jezik=125215

Fishbein, M., \& Ajzen, I. (1975). Belief, attitude, intention and behavior: An introduction to theory and research. Reading, MA: Addison-Wesley.

Groves, M. M., \& Zemel, P. C. (2000). Instructional technology adoption in higher education: An action research case study. International Journal of Instructional Media, 27(1), 57-65. Retrieved April 24, 2015, from ERIC database. (EJ605307)

Hair, J. F., Black, B., Babin, B., \& Anderson, R. E. (2010). Multivariate data analysis: A global perspective (6th ed.). Upper Saddle River, NJ: Prentice-Hall International.

Hermans, R. T. (2008). The impact of primary school teachers' educational beliefs on the classroom use of computers. Computers \& Education, 51, 1499-1509. doi:10.1016/j.compedu.2008.02.001

Hoyle, R. H. (2011). Structural equation modeling for social and personality psychology. London: Sage.

Hu, L., \& Bentler, P. M. (1999). Cutoff criteria for fit indexes in covariance structure analysis: conventional criteria versus new alternatives. Structural Equation Modeling, 6, 1-55. doi:10.1080/10705519909540118

Hu, P. J. H., Clark, T. H. K., \& Ma, W. W. (2003). Examining technology acceptance by school teachers: A longitudinal study. Information and Management, 41(2), 227-241. doi:10.1016/S0378-7206(03)00050-8

International Society for Technology in Education. (2007). ISTE standards: Students. Arlington, VA: Author. Retrieved from http://www.iste.org/docs/pdfs/20-14_ISTE_Standards-S_PDF.pdf

Joreskog, K., \& Goldberger, S. (1975). Estimation of a model with multiple indicators and multiple causes of a single latent variable. Journal of American Statistical Association, 70, 631-639.

doi:10.1080/01621459.1975.10482485 
Jöreskog, K. G., \& Sörbom, D. (1996). LISREL 8: User's reference guide. Chicago, IL: Scientific Software International.

Kadijevich, D. J. (2012). TPCK framework: Assessing teachers' knowledge and designing courses for their professional development. British Journal of Educational Technology, 43(1), E28-E30. doi:10.1111/j.1467-8535.2011.01246.x

Kiraz, E., \& Ozdemir, D. (2006). The relationship between educational ideologies and technology acceptance in pre-service teachers. Educational Technology and Society, 9(2), 152-165. Retrieved from http://www.ifets.info/journals/9_2/13.pdf

Klem, L. (2000). Structural equation modeling. In L. Grimm \& P. Yarnold (Eds.), Reading and understanding more multivariate statistics (pp. 227-260). Washington, DC: American Psychological Association.

Kline, R. B. (2010). Principles and practice of structural equation modeling (3rd ed.). New York, NY: Guilford Press.

Lagrange, J. (1999). Complex calculators in the classroom: Theoretical and practical reflections on teaching pre-calculus. International Journal of Computers for Mathematical Learning, 4(1), 51-81. doi:10.1023/A:1009858714113

Lai, C., Wang, Q., \& Lei, J. (2012). What factors predict undergraduate students' use of technology for learning? A case from Hong Kong. Computers \& Education 59 , 569-579. doi:10.1016/j.compedu.2012.03.006

Lampert, M., \& Ball, D. L. (1998). Teaching, multimedia, and mathematics: Investigations of real practice. New York, NY: Teachers College Press.

Lim, C. P., \& Khine, M. S. (2006). Managing teachers' barriers to ICT integration in Singapore schools. Journal of Technology and Teacher Education, 14(1), 97-125. Retrieved from http://www.editlib.org/p/5339

Lloyd, G. M., \& Wilson, M. (1998). Supporting innovation: The impact of a teacher's conceptions of functions on his implementation of a reform curriculum. Journal for Research in Mathematics Education, 29(3), 248-274. Retrieved from http://www.jstor.org/stable/749790

Mardia, K. V. (1970). Measures of multivariate skewness and kurtosis with applications. Biometrika, 37(3), 519-530. doi:10.1093/biomet/57.3.519

Mayer-Smith, J., Pedretti, E., \& Woodrow, J. (2000). Closing of the gender gap in technology enriched Science Education: A case study. Computers \& Education, 35, 51-63. doi:10.1016/S0360-1315(00)00018-X

McDonald, R. P., \& Ho, R. H. (2002). Principles and practice in reporting structural equation analyses. Psychological Methods, 7, 64-82. doi:10.1037//1082-989X.7.1.64

Mishra, P., \& Koehler, M. (2006). Technological pedagogical content knowledge: A framework for teacher knowledge. Teachers College Record, 108(6), 1017-1054. Retrieved from http://www.tcrecord.org/Content.asp?ContentID=12516

Motaghian, H., Hassanzadeh, A., \& Moghadam, D. K. (2013). Factors affecting university instructors' adoption of web-based learning systems: Case study of Iran. Computers \& Education, 61, 158-167. doi:10.1016/j.compedu.2012.09.016

Mueller, J. W., Wood, E., Willoughby, T., Ross, C., \& Specht, J. (2008). Identifying discriminating variables between teachers who fully integrate computers and teachers with limited integration. Computers \& Education, 51, 1523-1537. doi:10.1016/j.compedu.2008.02.003

Mumtaz, S. (2000). Factors affecting teachers' use of information and communications technology: a review of the literature. Technology, Pedagogy and Education, 9(3), 319-342. doi:10.1080/14759390000200096

Ong, C., \& Lai, J. (2006). Gender differences in perceptions and relationships among dominants of e-learning acceptance. Computers in Human Behavior, 22, 816-829. doi:10.1016/j.chb.2004.03.006

Pan, S., \& Jordan-Marsh, M. (2010). Internet use intention and adoption among Chinese older adults: From the expanded technology acceptance model perspective. Computers in Human Behavior, 26, 1111-1119. doi:10.1016/j.chb.2010.03.015

Park, S. Y. (2009). An analysis of the Technology Acceptance Model in understanding university students' behavioral intention to use e-Learning. Educational Technology \& Society, 12(3), 150-162. Retrieved from http://www.ifets.info/journals/12_3/14.pdf

Partnership for 21st Century Skills. (n.d.). Framework for 21st century learning. Retrieved from http://www.p21.org/storage/documents/1._p21_framework_2-pager.pdf 
Pierce, R., \& Ball, L. (2009). Perceptions that may affect teachers' intention to use technology in secondary mathematics classes. Educational Studies in Mathematics, 71, 299-317. doi:10.1007/s10649-008-9177-6

Pynoo, B., Tondeur, J., Van Braak, J., Duyck, W., Sijnave, B., \& Duyck, P. (2012). Teachers’ acceptance and use of an educational portal. Computers \& Education, 58, 1308-1317. doi:10.1016/j.compedu.2011.12.026

Raykov, T., \& Marcoulides, G. A. (2008). An introduction to applied multivariate analysis. New York, NY: Taylor \& Francis.

Ruthven, K. (2009). Towards a naturalistic conceptualisation of technology integration in classroom practice: the example of school mathematics. Education \& Didactique, 3(1), 131-152. Retrieved from http://educationdidactique.revues.org/434

Schepers, J., \& Wetzels, M. (2007). A meta-analysis of the technology acceptance model: investigating subjective norm and moderation effects. Information \& Management, 44, 90-103. doi:10.1016/j.im.2006.10.007

Schumacker, R. E., \& Lomax, R. G. (2010). A beginner's guide to structural equation modeling (3rd ed.). New York, NY: Routledge.

Shulman, L. S. (1986). Those who understand: Knowledge growth in teaching. Educational Researcher, 15, 4-14. Retrieved from http://www.jstor.org/stable/1175860

Star, J., \& Strickland, S. (2007). Learning to observe: Using video to improve preservice mathematics teachers' ability to notice. Journal of Mathematics Teacher Education, 11, 107-125. doi:10.1007/s10857-007-9063-7

Taylor, S., \& Todd, P. (1995). Understanding information technology usage: A test of competing models. Information Systems Research, 6(2), 144-176. doi:10.1287/isre.6.2.144

Teo, T. (2009). Modelling technology acceptance in education: A study of pre-service teachers. Computers \& Education, 52, 302-312. doi:10.1016/j.compedu.2008.08.006

Teo, T. (2010). A path analysis of pre-service teachers' attitudes to computer use: Applying and extending the Technology Acceptance Model in an educational context. Interactive Learning Environments, 18(1), 6579. doi:10.1080/10494820802231327

Teo, T. (2011). Factors influencing teachers' intention to use technology: Model development and test. Computers and Education, 57, 2432-2440. doi:10.1016/j.compedu.2011.06.008

Teo, T. (2012). Examining the intention to use technology among pre-service teachers: An integration of the Technology Acceptance Model (TAM) and Theory of Planned Behavior (TPB). Interactive Learning Environments, 20(1), 3-18. doi:10.1080/10494821003714632

Teo, T. (2013). A comparison of non-nested models in explaining teachers' intention to use technology. British Journal of Educational Technology, 44(3), E81-E84. doi:10.1111/j.1467-8535.2012.01350.x

Teo, T., Luan, W. S., Thammetar, T,. \& Chattiwat, W. (2011). Assessing e-learning acceptance by university students in Thailand. Australasian Journal of Educational Technology, 27(8), 1356-1368. Retrieved from http://ascilite.org.au/ajet/submission/index.php/AJET/article/view/898

Teo, T., Ursavas, O. F., \& Bahcekapili, E. (2012). An assessment of pre-service teachers' technology acceptance in Turkey: A structural equation modeling approach. The Asia-Pacific Education Researcher, 21(1), 199-210. Retrieved from http://www.ejournals.ph/index.php?journal=TAPER\&page=article\&op=view\&path[]=4827\&path[]=501 7

Turner, M., Kitchenham, B., Brereton, P., Charters, S., \& Budgen, D. (2010). Does the technology acceptance model predict actual use? A systematic literature review. Information and Software Technology, 52, 463479. doi:10.1016/j.infsof.2009.11.005

United Nations Educational, Scientific and Cultural Organization. (2002). Information and communication technologies in teacher education: A planning guide. Retrieved from http://unesdoc.unesco.org/images/0012/001295/129533e.pdf

United Nations Educational, Scientific and Cultural Organization. (2011). World data on education (7th ed.). Paris: Author. Retrieved from http://www.ibe.unesco.org/fileadmin/user_upload/Publications/WDE/2010/pdf-versions/Serbia.pdf

United Nations Educational, Scientific and Cultural Organization. (2013). Technology, broadband and education, advancing the education for all agenda:A report by the Broadband Commission Working Group on Education. Paris: Author. Retrieved from http://unesdoc.unesco.org/images/0021/002196/219687e.pdf 
Venkatesh, V. (2000). Determinants of perceived ease of use: Integrating control, intrinsic motivation, and emotion into the technology acceptance model. Information Systems Research, 11(4), 342-365. doi:10.1287/isre.11.4.342.11872

Venkatesh, V., \& Davis, F. D. (2000). A theoretical extension of the technology acceptance model: Four longitudinal field studies. Management Science, 46, 186-204. doi:10.1287/mnsc.46.2.186.11926

Venkatesh, V., Morris, M., Davis, G., \& Davis, F. D. (2003). User acceptance of information technology: Toward a unified view. MIS Quarterly, 27(3), 425-478. Retrieved from http://www.jstor.org/stable/30036540

Wachira, P., \& Keengwe, J. (2011). Technology integration barriers: Urban school mathematics teachers' perspectives. Journal of Science Education and Technology, 20, 17-25. doi:10.1007/s10956-010-9230-y

Yuen, A. H. K., \& Ma, W. W. K. (2008). Exploring teacher acceptance of E-learning technology. Asia-Pacific Journal of Teacher Education, 36(3), 229-243. doi:10.1080/13598660802232779

Corresponding author: Timothy Teo, timothyteo@umac.mo

Australasian Journal of Educational Technology @ 2015.

Please cite as: Teo, T., \& Milutinovic, V. (2015). Modelling the intention to use technology for teaching mathematics among pre-service teachers in Serbia. Australasian Journal of Educational Technology, 31(4), 363-380. 